\title{
METAPHYSICS OF REALITY: PRAGMATICO-ANALYTIC INTERPRETATION OF WITTGENSTEIN'S PHILOSOPHICAL APPROACH
}

\author{
Andrii Synytsia \\ Ivan Franko National University of Lviv (Ukraine)
}

\begin{abstract}
The article examines Ludwig Wittgenstein's views on the world and human beings in it. It is emphasized that the philosopher, in addition to paying a lot of attention to the study of language, which determined the basis of his method of cognition, followed a number of worldview ideas about reality. They were supported by the achievements of physics of that time, although Wittgenstein himself argued that the study of reality is not possible without understanding the metaphysical issues concerning the unspeakable, supernatural, spiritual, and so on. It shows how Wittgenstein interpreted the world and reality, distinguished between different levels of being, studied logical atoms, not laws, analyzed facts, not things, comprehended not only the macrocosm but also the microcosm, and as a result built a pragmatic ontological-cosmological conception, in which human and the way of their being in the world occupied a significant place.

Keywords: reality; world; logical atom; fact; object; microcosm; Wittgenstein
\end{abstract}

\section{Introduction}

Each philosophical system is based on the worldview beliefs of its author. However, when in the process of research the methodology becomes decisive, it is not entirely clear how the thinker themselves interprets a certain phenomenon or process. In the case of analytic philosophy, such theoretico-methodological feature is especially noticeable, because within this philosophical tradition, the solution of philosophical questions took place through the analysis of language, which has become a true reality and the subject of lively analytic debates. Largely thanks to the efforts of Ludwig Wittgenstein, language analysis has become a defining key to understanding our thinking. At some point, analytic philosophizing began to develop according to the following Wittgenstein's statement: "Philosophy is a battle against the bewitchment of our intelligence by means of language" (Wittgenstein, 1968: § 109). Analyzing the content of Wittgenstein's philosophy, it would be wrong to say that it is logical to follow from this statement that in order to study the phenomena of objective reality, it is enough to analyze only language. Moreover, it 
does not follow from this statement that language is the only key to understanding of the reality.

To understand how Wittgenstein himself defined reality, it is necessary to deconstruct his philosophical method and find out what underlies it. In this way it will be possible to clarify both ontological and cosmological ideas, the latter of which have only recently begun to attract the attention of researchers, who, in particular, tried to offer an analysis of natural phenomena and the world from the standpoint of Wittgenstein's philosophy. However, despite the fact that, for example, Nikolay Milkov writes about "philosophical cosmology" in Wittgenstein (Milkov, 2020: 17), Chon Tejedor analyzes physics in the light of the philosophy of the Austrian thinker (Tejedor, 2020), and Yoshihiro Maruyama reflects on certain aspects of quantum physics and cognitive science from a Wittgensteinian Perspective (Maruyama, 2020), it should be noted that Wittgenstein's metaphysical ideas about the nature of reality within his cosmological concept have remained uninvestigated.

\section{Distinction of the world and reality}

Interestingly, reflections on the world were one of the determinants for the formation of Wittgenstein's philosophical worldview. At the age of 16, as Gertrude E. M. Anscombe remarked, he was "greatly impressed by Schopenhauer's theory of the 'world as an idea' (though not of 'the world as will')" (Anscombe, 1959: 12). The study of the idea of the world immersed Wittgenstein in the field of metaphysics, although he sought to clearly understand what can be said about the reality, and what would be better to remain silent (cf: Wittgenstein, 1922: § 7). Later, in his "Notebook, 1914/1916" (Wittgenstein, 1961) and in the "Tractatus" (Wittgenstein, 1922: $\S \S 1-263,6.1-7)$, Wittgenstein tried to comprehend the idea of the world and possible ways of expressing it in language. His cosmological reflections were inspired by the ideas of theoretical physicists Heinrich Hertz and Ludwig Boltzmann, whose research has made the understanding of the nature of the microworld more thorough (Kjaergaard, 2002; Preston, 2017). However, Wittgenstein realized that no matter how much thinkers focus only on understanding the questions of physics, there will always be a number of metaphysical questions in science.

As an analytic thinker, Wittgenstein was critical of the metaphysical systems of the past. He preferred to consider directly the subject of his own research, rather than the reasoning of his predecessors. Moreover, thinkers of the past could not know many things about the world. These things became known only through the development of natural science. At the end of the XIX - beginning of the XX century there was a real breakthrough in science: at that time scholars not only clearly explained the internal structure of matter (both at the atomic and subatomic level), but also showed that in the microworld there are some other laws incomprehensible to us. For example, the behavior of quantum objects, which from 
the observer's point of view behave both as elementary particles and as waves, was at odds with our usual logic. Moreover, this state of affairs required a new metaphysics. In Wittgenstein's pragmatico-analytic interpretation, metaphysical knowledge, although related to the analysis of non-empirical entities, was not less logical. Such knowledge should reflect the logic of the Universe, and therefore clearly express the features of the research subject of metaphysics - reality.

Wittgenstein is known to have begun the "Tractatus" by understanding ontologico-cosmological ideas, even though they were the result of his philosophical research on the theory of logic $(1912-1914)$. As Hans-Johann Glock explained: “... although the Tractatus is concerned with symbolic representation (Preface), it starts with ontology, since the nature of representation, and of what represents (thought/language), is isomorphic with the nature of what is represented (reality)" (Glock, 1996: 364). Wittgenstein gradually came to think about the nature of reality. At first he was interested in precisely the question of what the world is. In fact, he uses both the concepts of the world (Welt) and reality (Wirklichkeit, and in a similar sense Realität in $\S 5.5561$ and $\S 5.64$ "Tractatus"), between which there is a difference. Wittgenstein, describing the world, wrote only about such a basic characteristic of it as logic (Wittgenstein, 1922: § 3.031), regardless of whether it is a real world or an imagined one. In any case, they will have a form in common (Wittgenstein, 1922: $\S 2.022$ ). He used the term "reality" to denote the actuality that we express in propositions. In general, everything that is represented in language, within the logical world, and that which defines these boundaries or is beyond them (unspeakable), constitutes the whole world. Wittgenstein's concept of the world becomes the most general category, which includes everything that happens - both what can be expressed in language and the unspeakable, for example, the correlation between language and reality.

Influenced by the methodology of realism, Wittgenstein interpreted language as a reflection of reality and devoted considerable effort to the study of the mental picture of the world - the study of facts in logical space. According to him, we replace these facts with their pictures and can explore reality, because the logic of language corresponds to the logic of the Universe and brings us closer to understanding its nature. It follows that in order to approach the understanding of the nature of reality, from a pragmatico-analytic perspective it will not be enough to study only reality itself or to understand how our language (and thinking as something not identical to it) works, it will also be necessary to comprehend what lies beyond them.

\section{Atoms, not laws}

However, to begin with, it would be important to understand what is within those limits and what that limit is. In Wittgenstein, reality is dynamic by nature. Changes in it occur both at the phenomenal and at the substantive levels. The Austrian thinker realized that in order to study reality, it is necessary to have a 
developed formal system with such syntactic means that would make it possible to capture all aspects of a dynamically changing world. It is no coincidence that Wittgenstein, thinking about the possibilities of language, claimed: "In the proposition there must be exactly as many things distinguishable as there are in the state of affairs, which it represents" (Wittgenstein, 1922: § 4.04). In this regard, he developed the idea of a dynamic logical picture of the world and focused on Hertz's Dynamic Models in the theory of mechanics.

Describing such models, Hertz, as it is known, stated: "The relation of a dynamical model to the system of which it is regarded as the model, is precisely the same as the relation of the images which our mind forms of things to the things themselves" (Hertz, 1899: 177). This reasoning could indeed have influenced Wittgenstein's concept of "logical representation". However, it would be an exaggeration to assume, as Andreea Esanu does, that "Ludwig Wittgenstein's concept of 'logical representation', seen as a landmark for what human reasoning is about, is an intricate analogue to the Hertzian 'dynamic models' from the Principles of Mechanics" (Esanu, 2013: 131). Wittgenstein's conception did not exclude the metaphysics of reality, it was not built only as an interpretation of reality on the model of classical physics (mechanics). Wittgenstein explained the dynamics of processes in reality through the interaction between objects (logical atoms). The appeal to objects, rather than the natural correlations between them, was caused by his doubts that the laws themselves were immutable. Under such conditions, forecasting future events seemed futile. Wittgenstein even stated: "That the sun will rise tomorrow, is an hypothesis; and that means that we do not know whether it will rise" (Wittgenstein, 1922: § 6.36311). In other words, Wittgenstein did not rule out the possibility of changing the essence of the laws themselves under the influence of certain factors.

Therefore, the basic categories of the Wittgenstein's ontologico-cosmological conception were not laws but atoms (in the logical, not the physical sense). The notion of law seems very general to Wittgenstein, and therefore the description of the world made by law will also be too general (Wittgenstein, 1922: $\S 6.3432$ ). When we deal with the real world, we look for laws that could describe our practical experience. But one can hardly hope to find such laws on the basis of logical justification. In the case of induction, we obtain a psychological justification of the laws, and hence the possibility of the probability of a certain future event that could not have been predicted. Wittgenstein argued that: "At the basis of the whole modern view of the world lies the illusion that the so-called laws of nature are the explanations of natural phenomena" (Wittgenstein, 1922: § 6.371). In this case, it is important as the basic elements of the ontology to substantiate those entities for which one could be sure of their immutability. Under the influence of Bertrand Russell, Wittgenstein developed the foundations of a pluralistic "atomistic" ontology (Synytsia, 2020). According to it, the world is a set of independent atomic facts (combinations of two objects). 
Such atoms become the basic elements of reality. Wittgenstein considered them not as constructions of sensory data (in Russell's sense), but as objects that are the fixed and the existent (Wittgenstein, 1922: $§ 2.0271$ ). In fact, logical atoms, not real relations between things, should be further analyzed by the philosopher. Each atomic state of affairs should be represented by an elementary proposition (which combines the names that represent objects). The truth or falsity of such propositions does not depend on the truth or falsity of other elementary propositions. And although the nature of logical atoms is determined by the properties and relations between individual things, the differences between real and logical atoms would disappear if an ideal language could be created. To achieve this result, it would be necessary to be as scrupulous as possible in creating such a language. In this case, language would clearly become a picture of reality, and on the basis of logical analysis of language, scientists could investigate the ontology of the basic elements of the world. However, such a prospect turned out to be illusory, as Wittgenstein himself demonstrated in the later works. The relations between expressions in natural language are much more diverse than those in formal one. And if we take the pragmatic aspect of language, it becomes clear that some of the information we have is extralingual (for example, some of our intentions, feelings or aspirations). Learning language is only the first step towards understanding the nature of reality. At a certain stage in the development of analytic philosophy, it was clearly realized that without the study of the preconditions of language (for example, mind), language itself will remain a mystery to us. The cognitive turn in analytic research that took place in the second half of the twentieth century clearly demonstrated this idea (Synytsia, 2017: $202-227$ ).

\section{Facts instead of things}

If the scholars analyze only language, they will face the question of how to distinguish the real world from the imaginary one. Not every term in a language will necessarily indicate something that actually exists. Sometimes the same entity will actually be denoted by different words. For example, Wittgenstein quite pragmatically regarded objects, entities and things as synonymous (Wittgenstein, 1922: $\S 2.01$ ) and did not intend to give meaning to them in a formal way. Of course, it would be possible to give each of them specific features, but this will not affect the specifics of the relations between objects in the real world. According to Wittgenstein's ontologico-cosmological ideas, "the world divides into facts" (Wittgenstein, 1922: $\S 1.2$ ), although the most elementary of them, atomic facts, are nothing more than a "combination of objects" (Wittgenstein, 1922: $\S 2.01$ ). Thus, both categories - facts and objects - are significant in his philosophical conception. As an analytic thinker, Wittgenstein chose the facts because he understood that philosophical means were clearly not enough to study objects. Analyzing the meaning of "Tractatus", it becomes 
clear why this is so, because Wittgenstein himself expresses a number of his own ideas about the ontology of objects.

According to his conception, objects are ontologically primary to our language and mind. Knowing the objects, we come to understand the nature of the world. However, the only way to learn about the nature of a thing is to compare it with other things. The possibility to become part of atomic facts, that is, to be in a certain relation to other things, is one of the basic characteristics of a thing. If such a relation between things did not arise, we could not say anything about them. If there was only one thing, it could not be interpreted in terms of something else and in terms of parts of that thing, because the object itself is simple (Wittgenstein, 1922: $\S 2.02$ ). For their part, two things would already create the whole world. In logical space, even possible things would become facts. Unlike things, their configuration does not have to be stable. Things as the basic elements of reality determine the whole set of states of affairs.

Simple objects interact with each other, connecting as members of a chain (Wittgenstein, 1922: $\S 2.03$ ). They do not form a synthetic whole like universals. Each of the objects is an individual logical atom that remains identical to itself. In fact, all the changes that actually occur are the result of the appearance of some configurations between objects and the disappearance of other ones. These configurations are accidental. The number of their possible variants is limited by the logic of the Universe. What is necessary does not go beyond what is possible. Wittgenstein does not deny that the existing configurations of things could be different, however, they could not contradict logic.

Objects, not correlations between them, are ontological entities. Therefore, with the help of language, people in the language community denote objects, not correlation. It can be argued that, on the one hand, things as ontological entities are independent, because they remain identical to themselves in different states of affairs. On the other hand, they are related to atomic facts. Thus, their form of independence becomes a form of dependence (Wittgenstein, 1922: § 2.0122).

It is worth noting that objects themselves are devoid of the sensory qualities (such as color) that we assign to them. Therefore, we cannot understand what they are in themselves. However, as a result of the presence of objects, their characteristics can appear in our consciousness, and due to the presence of language, we can name and distinguish them in the process of communication. It is these objects that make up the substance of the world. As Wittgenstein explained: "The substance of the world can only determine a form and not any material properties. For these are first presented by the propositions - first formed by the configuration of the objects" (Wittgenstein, 1922: $\S 2.0231$ ). The substance of the world remains the same in the various possible worlds. Changing the configuration of things does not change the nature of the world. In this case, the objects themselves are not accidental, they exist necessarily. The presence of substance in the world enables the truth of propo- 
sitions. Considering the situation of the absence of substance, Wittgenstein concluded that in this case the truth of some propositions would depend entirely not on what really exists in the world, but on the truth of other propositions (Wittgenstein, 1922: $§ 2.0211)$. In other words, we would have to consider certain propositions as something necessary. However, it is clear that under such conditions very soon philosophical analysis would become relativistic, and any of its metaphysical components would have to be eliminated from the language of scientific theory. The substance of the world indicates the existence of something outside language. The language only contains an indication of the relation to the real world; the world itself is not in it. In general, substance as the totality of objects that are incompatible into a single whole, determines the facts, their content and form (the ability to be in the state of affairs, i. e. to be in space-time relations, to have different physical qualities and properties). However, the substance remains identical to itself; we know the facts.

When Wittgenstein said that "the world is the totality of facts, not of things" (Wittgenstein, 1922: $\S 1.1$ ), it was obviously a matter of perceiving the world from a human perspective, even though fact is an ontologically independent entity, part of the world (logical space), which is independent of any states of consciousness. Through the prism of fact, Wittgenstein demonstrated the connection between the language picture of the world and reality. The latter is independent of language and is not its attribute. Facts do not name physical objects, but show how they combine with each other or what properties they have. Thus, a fact can be expressed through a proposition, not a name. The fact captures how the things, which are the ontological equivalent of atomic expressions, combine. The logical form of the fact is similar to the logical form of the elementary proposition. However, sometimes only on the basis of logical analysis of the phenomena themselves (a posteriori) it is possible to find out what this form is (Wittgenstein, 1929: 163).

Explaining how the transition from reality to language takes place, and at the same time projecting the concept of the logical structure of language into reality, Wittgenstein clarified: "The proposition is a picture of reality" (Wittgenstein, 1922: $\S 4.01)$. These pictures do not exist on their own, but depend on the facts. They are their equivalents in logical space, a kind of medial term between facts and thoughts. Since the "form of representation" is common to reality and pictures (Wittgenstein, 1922: $\S 2.17$ ), it allows us to investigate reality and, for the most part, to reflect it correctly in thoughts and propositions.

It is this form that allows us to analyze not the facts external to us, but what is in our consciousness. This transition is perhaps the most controversial in Wittgenstein's philosophical conception of reality, as it replaces the object with a picture in cognition, although we do not in any way affect the coincidence of picture and object. To my mind, such a transition already contains the possibility of a certain addition to the methodology of neo-realism with pragmatic ideas. Of course, the 
influence of pragmatism on Wittgenstein's methodology became clearer only in his later works (Synytsia, 2020). However, the analysis of the possibility of such a pragmatic transition in "Tractatus" shows that it is somewhat incorrect to interpret the content of this work as an attempt to build only an ideal language, within which elementary propositions denote atomic facts. To understand the metaphysics of reality, it is important to go beyond this scheme.

\section{From macrocosm to microcosm}

Distinguishing things from facts is not only an attempt to separate logic from epistemology, but also an intention to show that the human themselves plays an important role in understanding knowledge about reality. At the metaphysical level, person is the subject who is "the limit of the world" (Wittgenstein, 1922: § 4.01). Of course, his interest in human themselves became more noticeable later, when Wittgenstein began to comprehend the specifics of the process of argumentation, as well as certain socio-psychological aspects of human nature. However, already in "Tractatus" he argued: "The world and life are one" (Wittgenstein, 1922: § 5.621). In other words, it is impossible to comprehend the essence of the world without analyzing the specifics of human life, full of our intentions and desires, knowledge, values, communication with others and so on. With the help of words we construct our own world and only strive to understand the world around us. To further emphasize the importance of the subjective in the evaluation of objective processes, Wittgenstein stated: "I am my world. (The microcosm.)" (Wittgenstein, 1922: $\S 5.63$ ). He first formulated this idea in his "Notebooks, $1914-1916$ " (October 12, 1916), although in both cases without explanation (Wittgenstein, 1961: 84). Clarifying that the human world should be interpreted as microcosm, Wittgenstein thus continued to develop the line of neo-realism, because it actually meant that what happens in the inner world of human is subject to the general laws of the Universe. Microcosm has no specific laws.

However, the inner world of human has its own uniqueness. What happens in the microcosm (our microworld) cannot be reduced solely to physical processes that could be reproduced elsewhere. Mental phenomena are characterized by integrity, rather than decomposing into many individual parts. Each phenomenon is already an individual, integral atom. Despite the fact that "the world is independent of my will" (Wittgenstein, 1922: $\S 6.373$ ), it would be a mistake to assume that our world is closed in on itself. This statement only means that the outside world is not a product of our will. A human can thoroughly know in the world only what is clearly achievable to their understanding. They are unable to understand this world in any other way, that is, not as a human. That is why Wittgenstein argued: "The subject does not belong to the world but it is a limit of the world" (Wittgenstein, 1922: $\S 5.632$ ). In other words, the subject is the limit of the world that they are able to understand. But is there something beyond the world we perceive? 
According to Wittgenstein, it is impossible to comprehend the nature of the world, thinking only of the natural level of being. In "Culture and Value" (recorded in 1929), he wrote about things that go beyond nature, about something metaphysical, including "... only one thing as higher than nature..." (Wittgenstein, 2006: 1e) and that "Only something supernatural can express the Supernatural" (Wittgenstein, 2006: 3e). In this way Wittgenstein somewhat concretized his reflections in the "Tractatus" on what is unspeakable (Wittgenstein, 1922: § 4.115) and inexpressible (Wittgenstein, 1922: § 6.522). Distinguishing between natural and supernatural levels of being, Wittgenstein actually followed Kant's epistemological reflection (Kant, 2020). Knowledge of the real world that we explore is expressed through the propositions of natural science. Another thing is when it comes to things that are supernatural and cannot be explored by the means of the natural sciences. These things concern not so much the world as our personal life, the manifestations of spiritual (ethical, aesthetic, religious) experience, that is, all those meanings and values that cannot be expressed in propositions, because they do not have a logical form. This experience is unique and cannot simply be reduced to some general ideas expressed in language. It is an integral and defining part of the human microcosm. The inner (spiritual) experience of human logically complements what is happening in the outer world. At the level of spiritual being, human comprehends the metaphysical foundations of the real world. And even in spite of their ineffability, they essentially remain conceivable, and therefore in some way recognizable.

\section{Conclusions}

Thus, the method of analysis that Wittgenstein used to study the world through the prism of language was based on clear ontologico-cosmological ideas. His conception of reality initially contained a number of metaphysical ideas devoted to the unspeakable in the being and the place of human in the process of comprehending the world. They were further developed and contributed to the pragmaticoanthropological turn in Wittgenstein's philosophy. As a result, the world, which he interpreted as a set of atomic facts, became a dynamic formation with natural and supernatural levels of being, with phenomena that can not always be expressed in language, but those that affect human life and their worldview. In any case, his metaphysical interpretation of reality was supported by the conclusions of science, although it clearly indicated that our understanding of the world far exceeds the possibilities of its scientific knowledge and requires a balanced analytic approach pragmatic in nature. One of the consequences of this approach in analytic philosophy was the study of human consciousness as a precondition for language. Wittgenstein's works influenced the formation of a new perspective of pragmatico-analytic philosophizing, within which the comprehension of human and the metaphysical foundations of their inner world are significant for understanding the nature of the real world. 


\section{REFERENCES}

Anscombe, G. E. M. (1959). An Introduction to Wittgenstein's Tractatus. London: Hutchinson University Library.

Esanu, A. (2013). Hertzian Dynamic Models in Ludwig Wittgenstein's Theory of Logic. Manager Journal, 17(1), 131 - 144.

Glock, H.-J. (1996). A Wittgenstein Dictionary. Oxford: Blackwell.

Hertz, H. (1899). The principles of mechanics: presented in a new form / transl. by D. E. Jones and J. T. Walley. London: Macmillan.

Kant, I. (2020) Kritik der Reinen Vernunft. Berlin, Boston: De Gruyter.

Kjaergaard, P. C. (2002). Hertz and Wittgenstein's Philosophy of Science. Journal for General Philosophy of Science, 33(1), 121 - 149. DOI: https://doi.org/10.1023/a:1020703303373.

Maruyama, Y. (2020). Quantum Physics and Cognitive Science from a Wittgensteinian Perspective: Bohr's Classicism, Chomsky's Universalism, and Bell's Contextualism. In: Wuppuluri, S., da Costa, N. C. A. (eds.). Wittgensteinian (adj.): Looking at the World from the Viewpoint of Wittgenstein's Philosophy (pp. 375 - 407). Cham: Springer nature Switzerland AG.

Milkov, N. (2020). Wittgenstein's Ways. In: Wuppuluri, S., da Costa, N. C. A. (eds.). Wittgensteinian (adj.). Looking at The World from the Viewpoint of Wittgenstein's Philosophy (pp. 7 -19). Cham: Springer nature Switzerland AG.

Preston, J. M. (2017). Wittgenstein, Hertz, and Boltzmann. In: Glock, H.-J., Hyman, J. (eds.). A Companion to Wittgenstein (pp. 110-123). Chichester, West Sussex: John Wiley \& Sons, Ltd, 2017.

Synytsia, A. (2017). Contemporary Analytic Philosophy: From the Pragmatics of Language to the Conceptualisation of Consciousness. Lviv: Ivan Franko National University of Lviv, Lviv. [in Ukraininan].

Synytsia, A. (2020). The Basics of Neo-Realist Cosmology: Bertrand Russell against Alfred North Whitehead. Philosophy and Cosmology, 25, 182 - 193. DOI: https://doi.org/10.29202/phil-cosm/25/15.

Synytsia, A. (2020). Pragmatic Interpretation of Knowledge in Wittgenstein's Later Philosophy. Filosofiya-Philosophy. 2020, 29(3), 231 - 239.

Tejedor, C. (2020). Wittgenstein on Physics. In: Wuppuluri, S., da Costa, N. C. A. (eds.). Wittgensteinian (adj.). Looking at the World from the Viewpoint of Wittgenstein's Philosophy (pp. 275 - 287). Cham: Springer nature Switzerland AG.

Wittgenstein, L. (1922). Tractatus Logico-Philosophicus. Trans. by C. K. Ogden. London: Kegan Paul, Trench, Trubner \& Co.

Wittgenstein, L. (1929). Some Remarks on Logical Form. Proceedings of the Aristotelian Society, 9 (Supplemental), $162-171$. 
Wittgenstein, L. (1961). Notebooks 1914 - 1916 / von Wright, G. H. \& Anscombe, G. E. M. (eds.), transl. by Anscombe, G. E. M. Oxford: Blackwell.

Wittgenstein, L. (1968). Philosophical Investigations. Transl. by G. E. M. Anscombe. Oxford: Blackwell.

Wittgenstein, L. (2006). Culture and Value. Trans. by P. Winch. Chicago: Chicago University Press.

$\triangle$ Prof. Dr. Andrii Synytsia ORCID iD: 0000-0002-0983-7187 Department of History of Philosophy Ivan Franko National University of Lviv Lviv, Ukraine E-mail: andrii.synytsia.edu@gmail.com 